\title{
Habitual Difference in Fashion Behavior of Female College Students between Japan and Thailand
}

\author{
Aliyaapon Jiratanatiteenun ${ }^{1}$, Chiyomi Mizutani ${ }^{2}$, Saori Kitaguchi ${ }^{3}$, Tetsuya Sato ${ }^{3}$, \\ Kanji Kajiwara ${ }^{4}$ \\ ${ }^{1}$ Department of Engineering Design, Kyoto Institute of Technology, Kyoto, Japan \\ ${ }^{2}$ Department of Textile and Clothing, Otsuma Women's University, Tokyo, Japan \\ ${ }^{3}$ The Center for Fiber and Textile Science, Kyoto Institute of Technology, Kyoto, Japan \\ ${ }^{4}$ Fibre Innovation Incubator, Shinshu University, Nagano, Japan \\ Email: cindy_emailbox@yahoo.com
}

Received September 28 ${ }^{\text {th }}$, 2012; revised October 30 ${ }^{\text {th }}$, 2012; accepted November $13^{\text {th }}$, 2012

\begin{abstract}
The purpose of this study is to elucidate a role of the street fashion as a habitual communication tool for the youth through the comparative study on the habitual behavior of the Japanese and Thai youths. The questionnaires concerning the fashion behavior were submitted to a total of 363 female college students in Japan and Thailand in 2011. The results revealed the significant differences in fashion behavior between the two countries, which were affected by the climate, personal income, and traditional lifestyle. The Japanese youths care much about their personal surroundings and adapt fashion as a communication tool for social networking to be accepted in a group. The Thai youths care less about fashion and seek for other tools for social networking. By the time of the survey, the Japanese street fashion has been already matured as a communication tool with a variety of expression ways and is transfiguring spontaneously by repeated diversification and integration of several fashion elements. On the other hand, Thai street fashion is in the early stage and has not yet fully developed to affect a way of personal communication. However, the Thai youths have been increasing interest in fashion as confirmed by the increasing popularity of domestic fashion magazines, and provide a potential for Thai street fashion to develop.
\end{abstract}

Keywords: Street Fashion; Thai Youth; Japanese Youth; Habitual Behavior; Youth Communication

\section{Introduction}

Thai garment and textile industry had been supported by the government since 1955 and the industry had significantly grown in 1971. By 1990, Thailand was placed in the top ten for world exporters of garments. In 2002, the Thai government initiated the Bangkok Fashion City project under the Ministry of Industry of Thailand in order to establish Bangkok as a regional fashion hub and to promote the Thai fashion in the international market (Pasukvanich, 2003). In addition, the government has supported young designers in the international arena, at present there are several Thai brands such as AB-Normal, Curated, and Painkillers that are known in the international markets (Nethin, 2012). Further, the success of Thakoon Panichgul's clothes in 2008, the most well known Thai-born fashion designer who designs clothes for Michelle Obama and other celebrities, has significantly influenced Thai fashion industry (Chirapongse, 2010). He was invited by the government for holding a workshop to incubate new designers and create exotic fashions. At the moment, the government seems to emphasize heavily on Thai luxury brands for the global market rather than the domestic market.

The emergence of Thai fashion in the international arena has increased awareness of fashion in Thai people, especially within the younger generation. Although Thai luxury brands have gained their reputation internationally and caught attention from domestic customers, the prices of these brands are too high for young people to afford. Foreign fashions from Western and Asian countries have significantly influenced Thai fashion where many teenagers imitated or adapted these fashions to their personal styles. International fast fashion brands such as Zara and Uniqlo are more popular among Thai youths than the domestic brands. These brands provided quality products representing a trendy lifestyle with affordable price.

In September 2007, Japan and Thailand celebrated the 120th Anniversary of the establishment of the diplomatic relations and now Japan is one of Thailand's foremost economic partners (Embassy of Japan in Thailand, 2012). Since then, two nations have conducted varieties of cultural exchanges on traditional and youth cultures. "Manga (comics)" and "anime (animation films)" were the first Japanese popular youth culture that attracted Thai youths in the 1980s, followed by other youth cultures including pop music, soap opera, and street fashion which have become popular among Thai teens. Japanese street fashion was introduced to Thailand in the late 1990s (Rakprayoon, 2002) and became one of the factors that generated a street fashion concept among Thai teens and the youth fashion industry (Sanook Campus, 2009). The street fashion in Thailand is characterized by small street shops owned by a designer or fashion producer. The design was mainly a copy from foreign fashion magazines, but gradually improved its quality to satisfy the customers. Since manga and anime were enthusiastically accepted by Thai youths at the early stage of the cultural exchange, Cosplay and Lolita fashions inspired the young Thai designers. However, Thai society is too conservative to allow such costumes on the street, so these fashions were not devel- 
oped into street fashion in Thailand but established as specific costumes for young people at fun parties. These fun parties have become popular entertainment for Thai youths, and often organized by special companies or the boutiques themselves.

Thailand is a tropical country where heat and humidity are high almost all year round. Most of the schools and colleges in Bangkok specify their uniform and the students are obliged to wear this every day. The situation was similar in Japan until the 1980s and it took almost 20 years for the Japanese to enjoy fashion as a tool of self-expression. In this context, the street fashion in Thailand is still immature, and could follow as in the footsteps of Japan. The aim of this study is to explore the fashion attitudes and fashion styles in a cross-cultural context in order to understand the differences and similarities of youth fashions between the two countries.

\section{Fashion and Young People}

In contemporary culture, fashion became a tool of personal identity and seems to attract people of all ages, especially teenagers. In Japan, street fashion provides an abundant vocabulary for inter-group communication. According to Koester and May (1985), teenagers seem to value fashion more than any other age group. Clothes are the most purchased items in the teenage consumer spending habits (MRI, 2003) and teenagers around the world spend a considerable sum on fashion items. For example American teenagers spent 33\% of their earning and allowance on clothing (Holdsworth, 2005), and Japanese high school girls spent approximately 275 USD monthly on clothing which was three times larger than the national average (Drake, 2001).

Japan is one of the countries where people are actively engaged in fashion. Japanese youth fashion or street fashion became a public phenomenon in the late 1980s when Kogal (literally meaning "little girl”) and Lolita were often mentioned in newspapers and other mass media (Miller, 2004). Those fashions emerged from rather isolated teenage girls from society in order to protect their identity. Both Kogal and Lolita are the symbolic styles of a school girl and a girl from a good family, respectively. The Kogal style was inspired by the high school uniform, while Lolita fashion was inspired by European court fashions such as Rococo, Victoria and Edwardian fashions (Kawamura, 2006; Neko, 2008). Cosplay was a kind of play to connect the players (mostly young female) to the virtual world by wearing the costumes of comic or anime characters. Cosplay and Lolita are the major components in the otaku culture and were two of the most characteristic fashions in Japan which have influenced other fashion styles (Jiratanatiteenun et al., 2010). Since the lack of verbal communication skill excluded otaku people from a general youth society, Lolita or Kogal fashion as well as Cosplay served as a communication tool for them to form a new society for themselves. In addition, these Japanese subcultures have caught national and global mainstream attentions, they have disseminated to other countries such as Thailand.

Although the early development of Thai's Cosplay has followed a Japanese model, Thai's Cosplay has expanded its activity in a different way. For example, Lolita fashion is regarded as a part of Cosplay activity. The Coplay events are financially supported by private companies as a commercial event for youths. Although Cosplay is getting more popular in Thailand and presently there are over thirty Cosplay events held annually, neither Cosplay nor Lolita have influence on Thai fashion. In addition, Korean fashion is popular among young people. In the early 2000s, Korea popular cultures such as pop music, video games, movies, TV dramas, and fashion have become popular in Thailand (Park, 2008; Ngamchitcharung, 2005). The Korean pop cultures have more influence on Thai youths, and have taken over the popularity of the Japanese pop culture in Thailand. Now a K-pop cover contest is more popular than the original Japanese Cosplay.

\section{Methodology}

The purpose of this study is to examine the differences of fashion behaviors, fashion consciousness, and fashion styles among female college students in two countries. In order to explore a cross-cultural study, the survey questionnaires were submitted to the total of 363 respondents from two countries, aged 18-23. The survey questionnaire was prepared in Japanese and then translated into English before being translated into Thai. Japanese respondents included 265 undergraduate female students in Tokyo, Japan, while Thai respondents included 98 undergraduate students in Bangkok, Thailand.

In order to collect detailed information on fashion styles from the respondents, the questionnaire was separated into two sections. The first section of the questionnaire consists of 83 questions which were divided into 4 main sub-sections concerning 1) fashion information sources; 2) purchasing factors; 3) shopping places; and 4) fashion consciousness and consumption behaviors. Here the respondents were asked to answer by marking a five-point scale from "Not at all" = 1 to "Very" = 5 . The second section concerns the personal fashion interest of the respondents such as their fashion styles and their favorite fashion magazines. All respondents were photographed in order to observe their fashion appearances and to make a comparison between Japan and Thailand. The popular fashion magazines in each country were surveyed to examine the fashion lifestyle of the youths.

\section{Results and Discussion}

\section{Sources of Fashion Information}

The mean value of the dependence on each fashion source is displayed in Figure 1. Here the point 5 denotes the source which the respondents rely heavily on, the point 3 the average dependence, and the point 1 no dependence.

The dependence of the fashion information source reflects the lifestyle and habitual behavior. Figure 1 indicates that the Thai youths are less influenced by other people's fashion philosophies compared to the Japanese youths. The results were further analyzed to confirm significant statistical differences by using Independent Samples t-Test. The statistical significance was found in all sources between Japanese and Thais $(p<.05)$ except for "artists" and "family members" $(p>.05)$.

The Japanese respondents received fashion information from more varieties of sources including "fashion magazines", "fashion shops”, "show windows”, "passers-by”, "shop staffs", and "friends" than the Thai respondents. The Japanese rely traditionally more on the real information sources such as "fashion magazines", "fashion shops", "passers-by" and "show windows" than the virtual information such as the "Internet" and "movies". These real sources are basically composed of the fashion styles directly provided by the fashion industry, but 


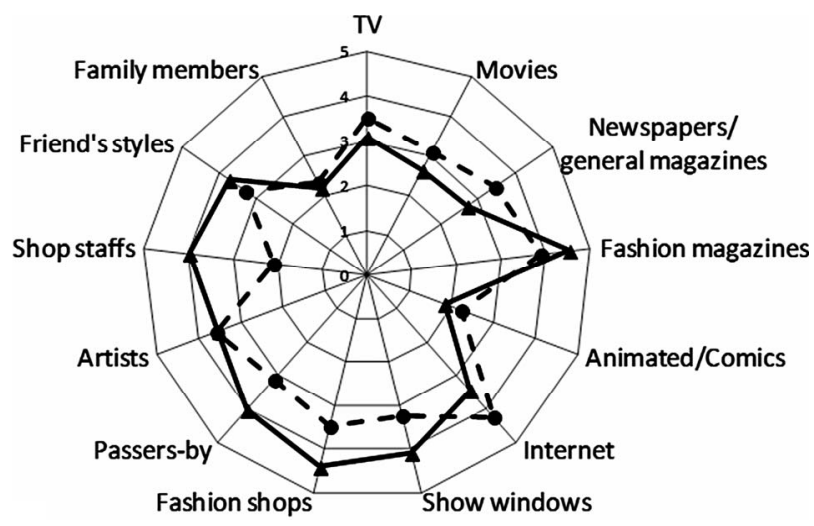

Figure 1.

The dependence mean value of the fashion information source: Solid line indicates Japanese, dashed line indicates Thais.

slightly modified/coordinated by wearers. Fashion magazines played an influential role in young Japanese women where they use the magazines for dress-up guidelines or copy the styles from the magazines (Luo, 2008). Since the Japanese youths are sensitive to their surrounding atmosphere, they tend to imitate and modify unintentionally the fashion of "passers-by", and to follow the advice from "shop staffs" and "friends". In consequence, they create their own styles rather spontaneously and feedback the influence anonymously to the fellow youths.

Conversely, the Thai respondents received more information from the sources such as the "Internet", "TV", "newspapers/general magazines", and "movies" than the Japanese. Among these sources, the Thai youths rely more on the information from indirect sources such as the "Internet", "artists", and "TV". The styles from these sources cannot be applied directly and should be modified by the wearers outside of the fashion industry. It is not surprising that the Thai teenagers observe fashion through these sources as they spend considerable hours watching TV (average 5.7 hours per day) and surfing the internet (average 3.1 hours per day) (Thai Post, 2010).

The mean values of "shop staffs" were very different between the two countries. In Japan, the shop staffs play an important role in setting new trends for teens, as many girls rely on their advice and would buy the same outfit that the shop staffs wear or recommends (Kawamura, 2006). Since the Thai shop staffs are obliged to wear uniforms, they cannot be a forerunner in setting the trends.

The influences from the "artists" and "family members" upon Japanese and Thai respondents were found to have a similar tendency with no statistical significance. Although in both countries the teenagers are moderately influenced by the "artists", artists in Japan are usually referred to J-pop singers, while in Thailand the artists are referred to the people who work in the entertainment and fashion businesses. The diversity of the artists in Thailand could have influenced the respondents in a larger extent than in Japan and the artists were one of the most influential sources in Thailand.

\section{Purchasing Factors}

The mean values of the purchasing factors follow a similar trend in Japan and Thailand (Figure 2). The lower mean values in Thailand could indicate the shopping frequency is less. The data were further analyzed to confirm the statistical significance

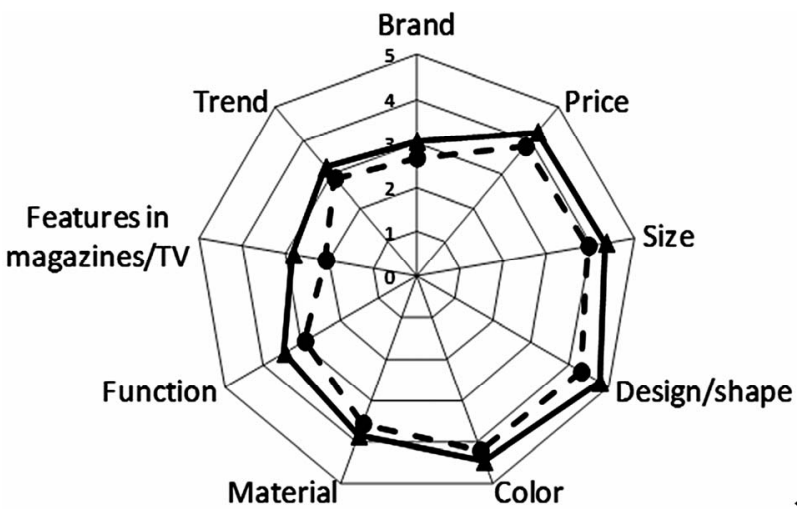

Figure 2.

The mean value of the purchasing factors: Solid line indicates Japanese, dashed line indicates Thais.

by the Independent Samples t-Test. The indicators of buying factors were found to have all statistical significant differences between both countries $(p<.05)$.

The "designs/shapes", "colors", and "sizes" were important factors for purchasing fashion articles in both countries. Although the Thai youths rely more on information from TV, the information has less impact on the actual purchasing behavior. This tendency indicates that the Thai youths enjoy the TV fashion but consider not as a real fashion. In fact the average mean value 2.09 (less than 3) confirms that the "features in TV/magazines" play almost no role in actual shopping. Monthly allowance could affect their buying behaviors, since the average monthly allowance for the Thai respondents was around 220 USD which is much lower than the prices of the fashion articles presented in the magazines/TV. The fashion articles appeared in those magazines/TV are imported brands or local luxury brands.

In Thailand, the western fashion magazines such as ELLE and Vogue are more popular than the local magazines. These magazines present western fashion styles with brand products. However, the styles presented in these magazines are not suitable for tropical climate in Thailand. Recently, many local fashion magazines such as Knock Knock appeared and introduce inexpensive exotic Thai fashions from local brands. These brands are becoming popular in the youth market, and indicate that inexpensive local brands will gain their market share in the near future as the Thai street fashion will mature.

\section{Shopping Places}

The respondents were asked to indicate their shopping places, in order to explore the similarities and differences of shopping habits in both countries. The mean values of each place are shown in Figure 3. The Independent Samples t-Test was employed in order to further examine the statistical significant differences.

The statistical significances $(p<.05)$ were found in all questions except for "receive from others" $(p>.05)$. Based on the results, the differences between the shopping places were observed. Three most popular shopping places were "outlet malls", "UNIQLO/GAP", and "select shops" for the Japanese respondents. "Department stores", "flea markets", and "luxury fashion boutiques" were the most popular shopping places among the Thai respondents. 


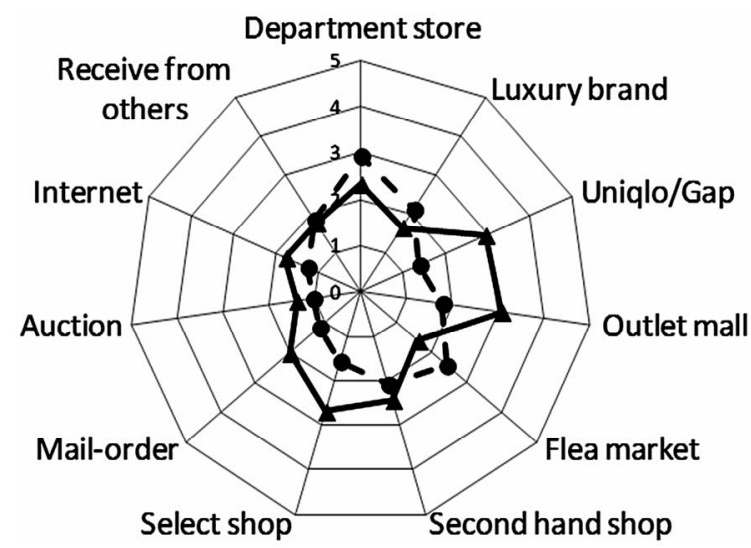

Figure 3.

The mean value of the shopping places: Solid line indicates Japanese, dashed line indicates Thais.

A first outlet mall opened in Japan in the 1990s (Coughlan \& Sobeman, 2004) and became popular among Japanese consumers of all ages. At present, there are over 30 outlet malls operating in Japan, where they sell local and global brand products at reasonable prices. On the other hand, a first outlet mall opened in Thailand in the 2000s by local fashion retailer and manufacturer (Pena House, 2007). Nowadays, there are over 10 outlet malls operating in Thailand but they are popular only to a particular group of people. In addition, "Uniqlo", "Gap”, and "select shops" were popular among the Japanese. Uniqlo and Gap are famous for quality products with affordable price, and the economic recession in 2007 (Abe, 2010) have increased the popularity of these brands among Japanese teens.

Select shops are small boutiques that sell fashion items from different brands selected by shop owners. Select shops, especially in Ura-hara (a back side of Harajuku), Tokyo, have been popular among Japanese teens since the 1990s because of their characteristic collections distinct from any mainstream fashions (Kawamura, 2006). In Thailand, select shops are referred to as small boutiques that sell selected items or boutiques that sell limited items designed by shop owners. Many select shops with various fashion styles are located in Siam Square in the center of Bangkok as shown in Figure 4. Siam Square is famous for shopping places and tutoring schools, where teens from secondary school to college gather before and after classes. Recently, the fashion prices here have significantly increased due to the renting fee for shops in the area. In addition, the quality of fashion products here is not as high as those sold in the department stores. As the result, teens tend to shop in the "department stores" and "flea markets" that sell quality fashion items at a reasonable price.

Department stores were the most popular shopping places among the Thai respondents. Department stores first opened in 1956 in Bangkok (Wigglesworth \& Brotan, 1966) and were at their peak of influence in the retail trade in the 1990s after forming part of shopping centre complexes (Mandhachitara \& Lockshin, 2004; Blair et al., 2003). At present, there are over 60 department stores operating in Thailand. These stores are equipped with full-air conditioning and provide a comfortable atmosphere for the customers to spend their time idly in the stores. In addition, they sell quality products and promote sales frequently to keep the customers. In consequence, the department stores have become the most popular shopping places in Thailand.

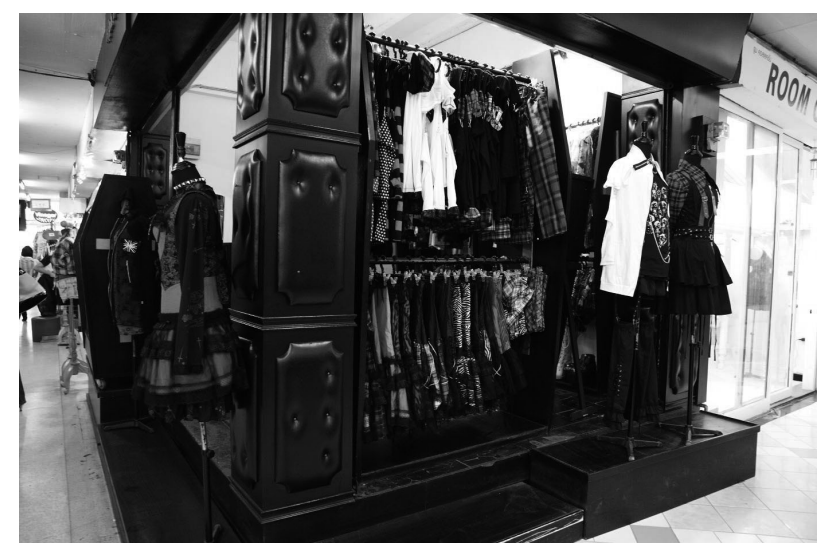

Figure 4.

Example of select shop at Siam Square, Bangkok.

Flea markets have been with the Thai society for decades. Jatujak market (Wongvittayapanich, 2011) is the most famous flea market in Thailand where a variety of products such as hand crafts, animals, and affordable fashion items are available. Jatujak market is popular among foreign and Thai customers of all ages, especially young people. Apart from Jatujak market, there are other flea markets in Bangkok such as Wang Lang and Major Ratchayothin market which are popular among Thai teens. Luxury products, especially handbags and sunglasses, from imported brands such as Louis Vuitton and Gucci have became popular among Thai people year by year. In 2011, this luxury market has grown 37.70\% from 2010 (Thansettakij, 2012). Although the average monthly income per household for Thai stood at 2800 USD (National Statistical Office, 2011) and a majority of youths receive their monthly allowances from their parents, these brands are popular among them. Thus, in order to own these products, many youths save their allowances to buy or ask for a gift from their parents.

It was found that there was no statistical significance on "receive from others" ( $p>.05)$ among the respondents from Japan and Thailand. In either country, the respondents prefer to buy the fashion items by themselves according to their taste.

\section{Fashion Consciousness and Consumption}

\section{Behaviors}

The differences of the mean values on fashion consciousness and consumption behaviors between two countries are shown in Figure 5. The t-Test results confirmed that the Thai and Japanese youths have a different attitude to fashion $(p<.05)$, except for two items "I have my favorite color" and "I wear trendy clothes even when I do not like them” where the statistical significances were .474 and .724 , respectively.

Japanese youths exhibited in general higher mean values in most questions except for the two questions mentioned above as the t-Test indicates a similar behavior in both countries. A marked difference is observed in the engagement in shopping. The shopping seemed to be an important factor in the daily life in Japan and spent a considerable time for shopping including window shopping. The Japanese youths decide what to buy after visiting several shops, while the Thai youths know what to buy in advance and spend less time in shopping. Here the Thai youths seem to be more confident in their appearance and know what styles would suit them without asking for advice from 


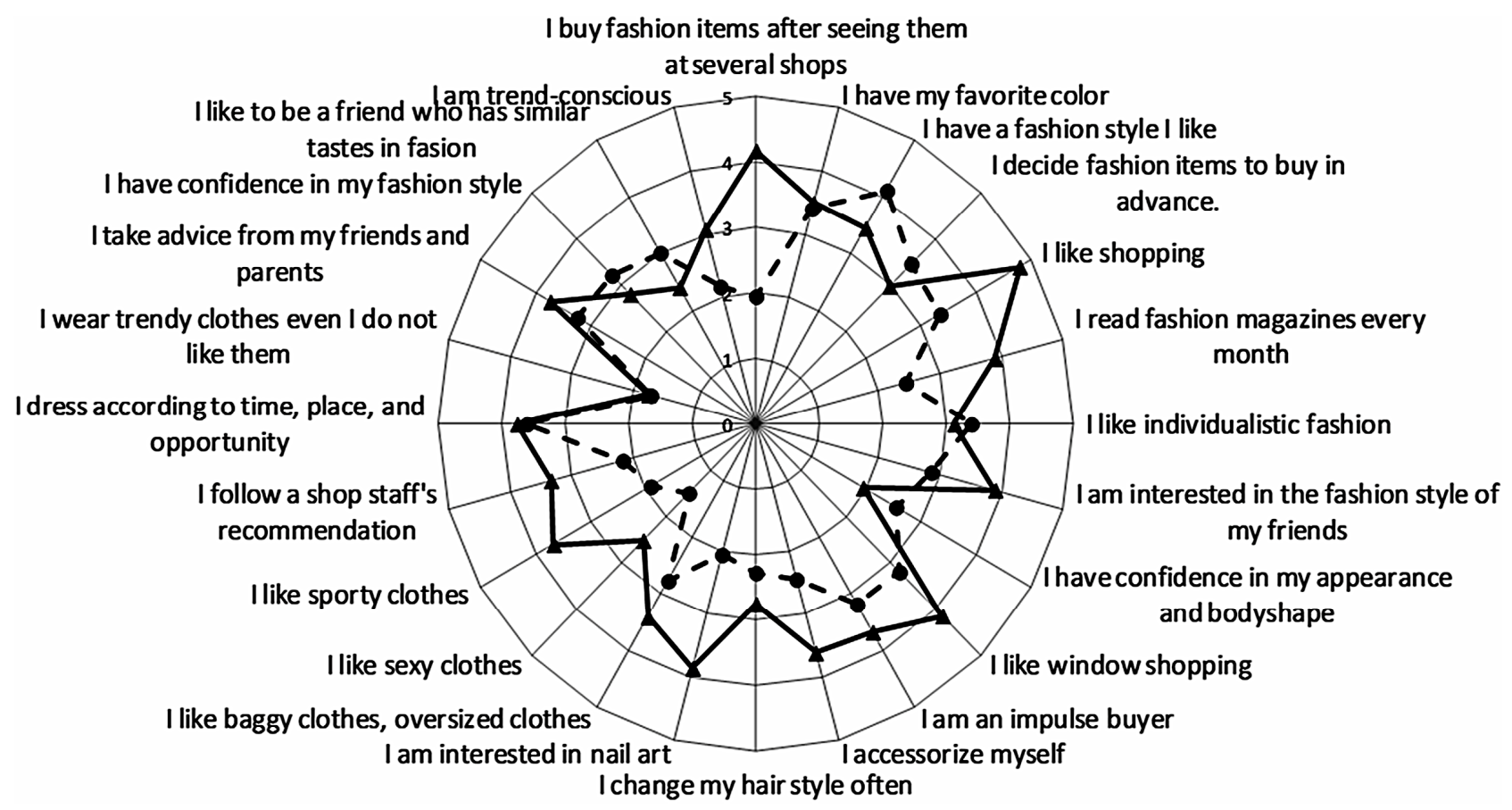

Figure 5.

The mean value of fashion consciousness and buying behaviors: Solid line indicates Japanese, dashed line indicates Thais.

others. The Thai youths prefer not to be outstanding as indicated by the less positive answers to the questions; "I like sporty clothes", "I like sexy clothes”, "I am interested in nail arts", "I change my hair style often", and "I accessorize myself". The different attitude to shopping may be due to the climate and the mode of the youth life style. Simply-spending time with friends is an important element in life for the Japanese youths, whereas the Thai youths require more action for a certain concrete purpose including eating together.

Monthly allowances were found to be little different in two countries. Thai respondents receive around 220 USD, while Japanese respondents receive around 300 USD per month. However, they spend money in different ways. Thai youths spend money more for eating with friends or chattering through mobile phone. In this context, fashion is not a primary concern for the Thai youths at present.

\section{Fashion Styles and Fashion Magazines}

The respondents were asked to indicate their fashion styles and favorite fashion magazines in order to make a comparison between two countries. The popular fashion styles in two countries are summarized in Table 1, while the examples of each style are shown in Figures $\mathbf{6}$ and $\mathbf{7}$.

The results showed that each country has their distinctive styles but casual is referred to in a similar way. However, the Japanese fashion types are more specifically addressed according to the lifestyle of the wearers, whereas a general term is used to describe the fashion type in Thailand. Japanese youth fashions are known for their uniqueness. Each style has its specific name, and is being transfigured consistently by the wearers. A tendency is observed that a group is formed by wearing a similar fashion style, and confirms the street fashion functioning as a communication tool, which is always being modified
Table 1.

The three most popular fashion styles between Japan and Thailand.

\begin{tabular}{ccc}
\hline \multirow{2}{*}{ Fashion styles } & \multicolumn{2}{c}{ Country } \\
\cline { 2 - 3 } & Japan & Thailand \\
\hline 1 & Casual & Casual \\
2 & Girly & Vintage \\
3 & Onei & Street \\
\hline
\end{tabular}

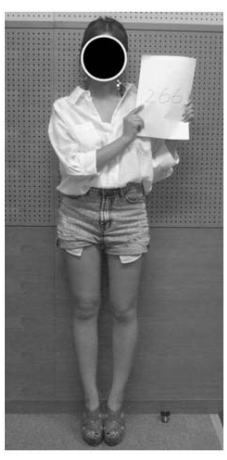

Casual

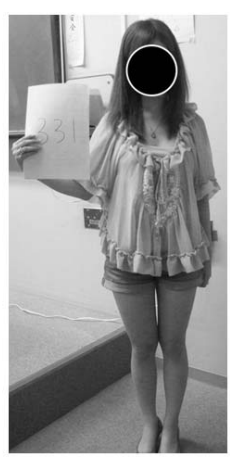

Girl

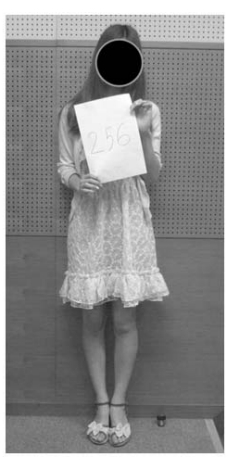

Onei
Figure 6.

Fashion styles among the Japanese respondents.

through a daily interaction in a group. A brief description of each style: Casual style is simple, non-distinctive, relaxed, and informal appearance. Girly is one of Casual sub-styles, with more feminine casual clothes that emphasized a cute concept. Onei costume is extremely feminine and affords a matured looking, but maintains the cuteness (kawaii concept) by decorating with lace and ribbon. 


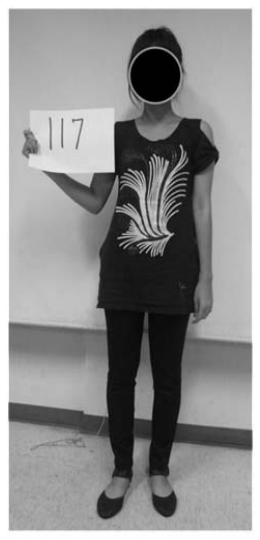

Casual

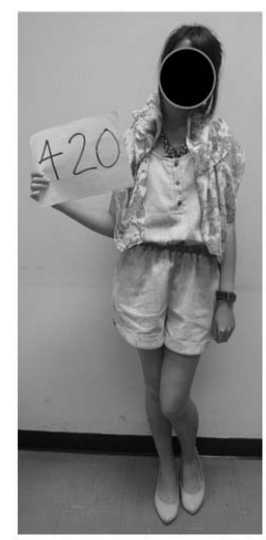

Vintage

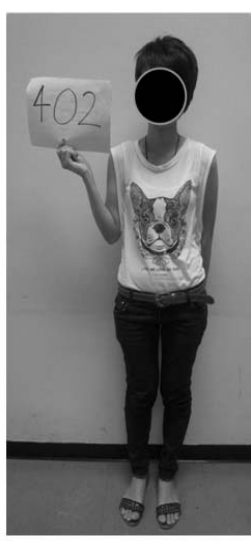

Street
Figure 7.

Fashion styles among the Thai respondents.

In contrast, Thai youth fashion is simple and less distinctive. A brief descriptive of each style: Casual style is simple, nondistinctive, relaxed, and informal appearance. Vintage clothing is inspired from fashion in the 1960-1980s. Street style is created by anonymous wearers but not by the fashion industry. Although Thai fashions have different names and evolution, all styles look similar with no distinctive characteristics. In addition, all of them consist of two main elements which are a t-shirt and any kind of bottom. A personal income (or monthly allowance) and the climate may restrict the diversity of fashion styles. The average of monthly income per household in Japan stood at 5200 USD (Statistics Bureau, 2012), while it is 1.8 times less in Thailand and may cast some limit for the dressing-up and the choice of fashion styles. In addition, the tropical climate in Thailand allows only the fashion styles to be simple and not sophisticated. Thus, the Thai fashions are less diverse than Japanese. Further, the definition of vintage style was found to be different between Japan and Thailand. Vintage style is referred to as second hand clothes in Japan, while it is referred to fashion inspired from the 1960-1980s in Thailand.

The five most popular fashion magazines are listed in Table 2 for each country.

Table 2 indicates that the local Japanese fashion magazines were popular among the Japanese. These magazines are owned by local publishers, and the fashion styles and beauty tips in these magazines are created by Japanese stylists.

As shown in the magazine ranking, two of Thai's local magazines (Cheeze and Knock Knock) are popular among the Thai respondents. However, the western magazines such as Seventeen, ELLE, and CLEO are also popular among them. Cheeze published the first issue in May 2004, after the trend of street fashion has disseminated to Thailand and the magazine was inspired mainly by the Japanese street fashion. Although Cheeze is relatively new in the Thai magazine industry, it has become significantly popular among the Thai youths, especially during 2008 and 2009. When it was first published, Cheeze contained with four sections which were Bangkok street fashion, shopping guide, beauty tips, and interview with celebrities. Cheeze now focuses mainly on the local street fashion in Thailand. The number of street fashion pages has increased from 25 to 70 percent of the book, and Cheeze's street target has expanded from Bangkok to other cities in Thailand such as
Table 2.

The popular fashion magazines between Japan and Thailand.

\begin{tabular}{ccc}
\hline \multirow{2}{*}{ Magazine ranking } & \multicolumn{2}{c}{ Country } \\
\cline { 2 - 3 } & Japan & Thailand \\
\hline 1 & ViVi & Cheeze \\
2 & Non-no & Seventeen \\
3 & Seda & ELLE \\
4 & Ray & Knock Knock \\
5 & Sweet and Zipper & CLEO \\
\hline
\end{tabular}

Chiang Mai and Khon Kaen. In addition, the influence of western fashion can be observed on Cheeze magazine, where many non-professional models are inspired by unsophisticated western fashions with T-shirt and any kind of bottom, and dark color. Knock Knock, first published in 2008 during the same time at the rise of the popularity of Thai street fashion. Knock Knock displays Thai fashions that are portrayed by young Thai models and celebrities, and street fashion section is provided with a small number of pages. On the other hand, the western fashion magazines sold in Thailand are directly translated from original editions, so that those magazines contain western fashion styles and beauty tips, with little emphasis on Thai local fashions. To summarize, it could be predicted from the popularity of Cheeze and Knock Knock that Thai street fashion will continue to grow and become more popular in the near future.

The contents of fashion magazines are also different between two countries, indicating that the focus of youth interests is different. In general Japanese fashion magazines contain several fashion pages, local street fashion snap shots, and beauty tips, while Thai fashion magazines have less fashion pages and contain non-fashion columns such as interview with celebrities health, and quizzes. The examples of fashion styles from the magazines are shown in Figures 8 and 9.

Although western fashion magazines are popular among the Thai respondents, these magazines seem to have no direct influence on the respondents' fashion behavior. Due to monthly income and the climate, the Thai respondents cannot adapt the styles provided in western magazines. These magazines are read just for entertainment purpose or to satisfy their fashion adoration. The ranking of Cheeze magazine has implied the interest of Thai youths in street fashion, and the potential of maturing street fashion as the expression of the self-identity among the Thai youths.

\section{Global Influences}

The comparison of the global fashion influences was carried out in this paper. The respondents were asked to indicate the city of their fashion inspirations. The results are shown in Table 3 .

Based on the results of the global influences, Paris has a highest influence on the Japanese respondents. Paris is known for one of the world's fashion capitals, and its fashion has highly impacted the global apparel business. France is much influenced by the Japanese pop arts in the mid-19th century, know as a Japonism, and in consequence a new art movement was initiated. Since then, France and Japan have enjoyed the 


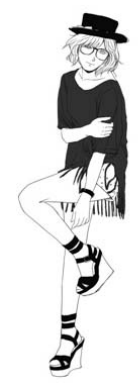

Fashion style from ViVi magazine

Figure 8.

Fashion styles from Japanese fashion magazines.
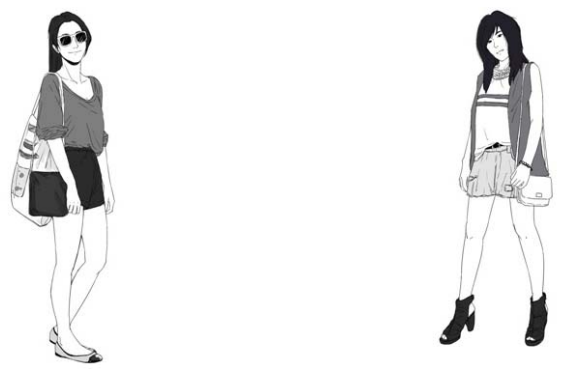

Fashion style from Cheeze magazine

Fashion style from Knock Knock magazine

Figure 9.

Fashion styles from Thai fashion magazines.

Table 3.

The city of fashion inspiration.

\begin{tabular}{ccc}
\hline \multirow{2}{*}{ City of inspiration } & \multicolumn{2}{c}{ Country } \\
\cline { 2 - 3 } & Japan & Thailand \\
\hline 1 & Paris & Bangkok \\
2 & Tokyo & Seoul \\
3 & London & London \\
\hline
\end{tabular}

cultural exchange to stimulate their traditional cultures. Fashion is not an exception, and many Japanese fashion designers have practiced their skill in Paris. Especially in 1920s, French cultures including pure arts, fashion, and entertainment had the highest impact on Japanese society (Slade, 2009). The economic growth in the 1970s enabled Japanese consumers to acquire French luxury goods, and the number of Japanese consumers travelled to Paris to satisfy their taste for French luxury brands, such as Louis Vuitton and Chanel (Steele et al., 2010). To date, both luxury and mainstream French fashions continue to influence the Japanese.

On the other hand, Bangkok was ranked as the most influential cities by the Thai respondents. The Thai domestic fashion business has been supported and promoted by the government since 2002 (Puangmalai, 2011). "ELLE Bangkok Fashion week", the biggest fashion show in Thailand, started in 1999 (Kaewthong, 2012) in order to encourage Thai fashion designers in the global market. The growth of Thai fashion industry has drawn attention of Thai people on Bangkok fashions and people are more aware of local styles. In addition, Thai people became more concerned with street fashion as a tool for self-expression. The Thai fashion industry is now realizing the potential of the domestic consumers, and began to produce the original fashion apparels for the domestic consumers. These apparels are unique in style and identified as a Thai style. Apart from Bangkok fashion, Thai teens also receive a lot of influences from Korea. Korean pop cultures such as movies, dramas, foods, and fashions have become popular among Thai-middle class youths since the early 2000s (Siriyuvasak \& Hyunjoon, 2007). Korean fashion is especially popular among Thai teenagers, and they adapt the Korean styles for their personal fashion style. The influence of Japanese youth culture including the Japanese street fashion used to have a big influence on the Thai youths in the early 1990s (Tidarat, 2002), but it is now replaced by a Korean pop culture. A better supply chain (easy to access) and less sophisticated fashion styles (easy to adapt) promoted the popularity of Korean fashion in Thailand.

\section{Conclusion}

Although the Japanese youths care much about their personal environment, they seem to attempt to be a little distinct from others while maintaining a fundamental similarity in clothing to indicate their dependency on a particular group. The Japanese youths collect fashion information from various sources including "fashion magazines", "passers-by", "shop staffs", "friends", "fashion shops", and "show windows". The information comprises the fashion information delivered directly from the manufacturers and the fashion information modified by the wearers. The shop staffs play an important role in Japan as a fashion forerunner who creates a new trend by coordinating various fashion items with new styles supplied from the apparel companies.

The street fashion in Thailand is necessarily restricted by the climate. The Thai youths are now interested in the fashion information, but rely more on the internet and TV/CM. The fashion in Thailand is still in the state of dawn, but the dawn breakers are appearing as shown in the styles appearing in the magazines such as "Cheeze" and "Knock Knock". However, the Thai youths spend more time and money on eating together and chattering through mobile phones, and the street fashion is not yet functioning as a social networking tool.

Shopping reflects the habitual behavior in both countries. The shopping frequency is low in Thailand, suggesting their time is more allocated to spending with friends and families for eating and chattering. The department store seems to their favorite place for shopping, because the department store in Thailand is well air-conditioned and provides the goods of reasonable quality with reasonable price. The Japanese department store tends to promote more luxury goods of a good quality. The quality assurance is an important business factor for the Japanese department stores, and the prices are necessarily high. Thus the Japanese youths shop more frequently at "outlet malls”, “Uniqlo”, “Gap”, and "select shops”.

The street fashion in Japan offers a diversity of styles characteristic to each street in Tokyo. The wearers arrange their style according to their personal surroundings and modify slightly according to their individuality. Naturally the street fashion in Japan transfigures consistently on the personal level, and in the end creates a new trend. On the other hand, Thai fashion styles were less characteristic and simple which could be resulted from the tropical weather, lower income, and lifestyle. 
There are so many fashion magazines available in Japan, which introduce a new trend not only for fashion but also for a lifestyle. Here each magazine has its own concept of fashion and lifestyle, and the Japanese youths can choose the fashion magazines according to their personal surroundings. A variety of street fashions available in town correspond to a diversified way of chattering among the Japanese youths.

Both western and local fashion magazines are popular in Thailand. The fashion magazines in Thailand serve more for entertaining individuals and no direct influence on Thai street fashion. The Thai youths are less engaged in fashion and the street fashion in Thailand is still immature. However, the increasing popularity of the local fashion magazines such as "Cheeze" and "Knock Knock" indicates the increasing interest in the street fashion and the change of the youth lifestyle.

\section{REFERENCES}

Abe, N. (2010). Japan's shrinking economy. URL (last checked 11 January 2012).

http://www.brookings.edu/opinions/2010/0212_japan_economy_abe. aspx

Blair, M., Armstrong, R., \& Murphy, M. (2003). The 360 degree brand in Asia. Hoboken, NJ: John Wiley \& Sons.

Chirapongse, K. (2010). 5 top bangkok fashion brands. CNNGO. URL (last checked 22 April 2012).

http://www.cnngo.com/bangkok/shop/bangkok-fashion-designers-57 8095

Coughlan, A., \& Sobeman, D. (2004). A survey of outlet mall retailing: Past, present, and future. INSEAD. URL (last checked 22 April 2012) http://flora.insead.edu/fichiersti_wp/inseadwp2004/2004-36.pdf

Drake, K. (2001). Kwest for kawaii. Time magazine world. URL (last checked 15 February 2012).

http://www.time.com/time/magazine/article/0,9171,131022,00.html

Embassy of Japan in Thailand (2012). Japan-Thailand relations. URL (last checked 15 February 2012). http://www.th.emb-japan.go.jp/en/relation/index.htm

Holdsworth, A. (2005). Teens spend more than some states, countries: Teens cash in. Window on state government. URL (last checked 20 July 2012).

http://www.cpa.state.tx.us/comptrol/fnotes/fn0508/teens.html

Jiratanatiteenun, A., Kitaguchi, S., Sato, T., \& Kajiwara, K. (2010). Dynamics of street fashion in Japan as represented by cosplay and lolita. Proceeding from The Textile Institute Centenary Conference, Manchester: The Textile Institute.

Kaewthong, S. (2012). Biography. URL (last checked 20 July 2012). http://www.kaiboutique.com/About

Kawamura, Y. (2006). Japanese teens as producers of street fashion. Current Sociology, 54, 748-801.

doi:10.1177/0011392106066816

Koester, A. W., \& May, J. K. (1985). Profiles of adolescents' clothing practices: Purchase, daily selection and care. Adolescence, 20, 97113.

Luo, X. (2008). Women's fashion magazines in Japan: Women vs. women's fashion magazines in relation to self-image creation and Consumption. Master's Thesis, Lund: Lund University.

Mandhachitara, R., \& Lockshin, L. (2004). Fast moving luxury goods: Positioning strategies for Scotch whisky in Thai department stores. International Journal of Retail \& Distribution Management, 32, 312319. doi:10.1108/09590550410538015
Miller, L. (2004). Youth fashion and changing beautification practices. In G. Mathews, \& B. White (Eds.), Japan's changing generations: Are young people creating a new society (pp. 83-98). Oxron, OX: Routledge Curzon.

MRI (2003). Teen market profile. Magazine Publisher of America. URL (last checked 19 July 2012). http://www.magazine.org/content/files/teenprofile04.pdf

National Statistical Office (2011). Personal income and its disposition: 2007-2009. Statistical Yearbook Thailand 2011. Bangkok: Thammada Press Co., Ltd.

Neko, N. (2008). Lolita and Japanese Society. URL (last checked 3 February 2012). http://www.lolitafashion.org/index.html

Nethin, N. (2012). Designers' room: An important step of Thai designers for international area. URL (last checked 12 April 2012). http://www.thanonline.com/index.php?option=com_content\&view=a rticle\&id=110509:dsigners-room-\&catid=171:pr\&Itemid=512

Ngamchitcharung, C. (2005). Korean teens: Great power in the era of the modern market, Maketeer, 6, 50-114.

Park, K. A. (2008). The growth of cultural industry and the role of Government: The case of Korea. Master's Thesis, Cambridge, MA: Massachusetts Institute of Technology.

Pasukvanich, C. (2003). Study highlights: Improvement of competitiveness of Thailand. Bangkok: Office of the National Economic and Social Development Board.

Pena House (2007). Business: Outletmall company limited. URL (last checked 4 July 2012). http://www.penagroup.com/business_outletmall.php

Rakprayoon, T. (2002). The diffusion of Japanese teenage culture on media in Thailand. Master's Thesis, Bangkok: Chulalongkorn University.

Sanook Campus (2009). Tokyo Street Fashion. Sanook.com. URL (last checked 4 July 2012)

http://campus.sanook.com/teen_zone/intrend_06008.php

Siriyuvasak, U., \& Hyunjoon, S. (2007). Asianizing K-pop: Production, consumption and identification patterns among Thai youth. Inter-Asia Cultural Studies, 8, 109-136.

doi:10.1080/14649370601119113

Slade, T. (2009). Japanese fashion: A cultural history. New York: Berg.

Statistics Bureau (2012). Summary of the latest month on family income and expenditure survey. Statistics Bureau, Ministry of Internal Affairs and Communications. URL (last checked 12 July 2012). http://www.stat.go.jp/english/data/kakei/156.htm

Steele, V., Patricia M., Yuniya K., \& Hiroshi N. (2010). Japan fashion now. Italy: Conti Tipocolor.

Thai Post (2010). Thai Kids addicted to Internet/TV. URL (last checked 12 July 2012). http://www.thaipost.net/node/18891

Thansettakij (2012). Brand name has conquered Thai's market. URL (last checked 12 July 2012).

http://www.thanonline.com/index.php?option=com_content\&amp;vi ew=article\&amp;id=110553:2012-03-02-14-33-04\&amp;catid=85:20 09-02-08-11-22-45\&amp;Itemid=417

Tidarat, R. (2002). The popularization of Japanese youth culture in the media in Thailand. Master's Thesis, Bangkok: Chulalongkorn University.

Tipparat (2011). Thai's garment industry. URL (last checked 12 July 2012). http://www.idis.ru.ac.th/report/index.php?topic=6449.0; wap2

Wigglesworth, E. F., \& Brotan, J. (1966). Retailing trends in Thailand. Journal of Retailing, Summer issue, 41-51.

Wongvittayapanich, N. (2011). Jatujak and bon marche market: The good management of the market places. URL (last checked 10 July 2012). http://www.tuhpp.net/files/FACT1-1.pdf 